\title{
A Research on the Effectiveness of Aerospace Quality Management System (Aqms) in the Aerospace Organisations in Bangalore
}

\author{
Gopikrishnan Nair TK, R. Gayatri
}

\begin{abstract}
Aerospace Organisations in the field of Aviation, Space \& Defence businesses are required to mandatorily obtain Aerospace Standard AS certification in order to enter the arena. Among the aerospace standards $A S 9100 \mathrm{D}$ can be taken for any generic $A, S \& D$ organization while AS9110C is applicable for MRO Organisations and AS $9120 B$ is applicable for organisations in the area of supply and distribution of aerospace items and components. The certification is awarded after a very thorough audit by International Aerospace Quality Group(IAQG) certified Aerospace auditing companies, called Certifying Bodies $(\mathrm{CB})$ and the certification process is quite expensive. This paper is critically analyzing whether the AS certified companies in Bangalore have obtained perceivable results in their operation after adoption of the stringent and expensive Aerospace Quality Management System(AQMS) certification conforming to the Aerospace Standard AS $9100 \mathrm{D}$ and whether the adopted procedures have incorporated QMS principles in their planned activities which can generate perceivable improvements in the organizational environment.
\end{abstract}

Key Words; Aviation, Space and Defence Organisations $(A, S \& D), \quad$ Aerospace Standard AS 9100D, International Aerospace Quality Group (IAQG), Aerospace Quality Management System (AQMS), Effectiveness of AQMS, Aerospace Auditing, QMS principles.

\section{INTRODUCTION}

In order to assure customer satisfaction, aerospace industry organizations must produce, and continually improve safe, reliable products that meet or exceed customer and regulatory requirements. The globalization of the aerospace industry, and the resulting diversity of regional/national requirements and expectations, has complicated this objective. End-product organizations face the challenge of assuring the quality of, and integration with, product purchased from suppliers throughout the world and at all levels within the supply chain. Aerospace suppliers and processors face the challenge of delivering product to multiple customers having varying quality expectations and requirements. The document (AS9100D) standardizes Quality Management System requirements for the aerospace industry.

Features of AS 9100D. The AS9100D standard provides guidance for suppliers, designers, and manufacturers alike, and is now a several-part-series of standards that cover inspection, maintenance, and the requirements for stockpile suppliers and distributors. Although the entire ISO 9001:2015 standard is contained within AS 9100D, it is only

\footnotetext{
Revised Manuscript Received on September 10, 2019.

Gopikrishnan Nair TK, Research Scholar, St.Peter's Institute of Higher Education and Research, Chennai, Tamilnadu, India.

(email id: gkn.50mba@gmail.com)

Dr. R. Gayatri, Adjunct Faculty, Saveetha School of Law, Chennai, Tamilnadu, India.

(email: gkn.46kmpla@gmail.com).
}

about $70 \%$ of the total standard. The balance is aerospacespecific programs and topics, most of which can be backtracked to directives issues by the FAA including airworthiness, part certification, and identification marking. Beyond the ISO portion, some of the requirements specific to the aerospace industry included in AS9100D are:

- Maintenance, reliability, and safety

- Configuration management

- First article inspection

- Verification of design, validation and testing processes

- Purchased product verification

- Product identification throughout its life cycle

- Work performed at an outside supplier's facility

- Special processes

- Technical documentation reporting and control

Essential requirement. Quality and reliability are essential for the aerospace industry, where errors, shortcuts, or lack of attention to detail can be fatal. A quality management system (QMS) helps to reduce risks, ensures consistency, and provides a reliable framework for the whole supply chain. Communication is essential, and this standard lists seven areas for consideration, from clarifying engineering requirements to managing test specimens, and right of access to suppliers' facilities. Developed by aerospace engineers in the USA and Europe, working closely with the International Standards Organization (ISO), AS9100D simplifies and standardizes the previous diversity of quality documentation. Now all aerospace manufacturers and suppliers worldwide require compliance to AS9100D as a condition of doing business. for any business which supplies this valuable and rapidly expanding sector, achieving AS $9100 \mathrm{D}$, the specific quality standard for the aerospace industry, is now an essential step, demonstrating throughout the supply chain that safety, reliability, and confidence are top of the priority list.

\section{REVIEW OF LITERATURE}

\section{Global Aerospace Industry - Top 10 Countries}

- The aerospace industries of the top ten countries are worth $\$ 731$ billion $-87 \%$ of the global industry

- The United States comprises almost $49 \%$ of the world aerospace total, more than the next 25 countries combined 
A Research on the Effectiveness of Aerospace Quality Management System (Aqms) in the Aerospace Organisations in Bangalore

\begin{tabular}{|c|c|c|}
\hline Ranking & Country & Industry Size (\$B) \\
\hline 1 & & \\
\hline & United States & $\$ 408.4$ \\
\hline 2 & & $\$ 69.0$ \\
\hline & France & $\$ 61.2$ \\
\hline 3 & & \\
\hline & China & \\
\hline 4 & & $\$ 48.8$ \\
\hline & United Kingdom & $\$ 27.1$ \\
\hline 5 & Germany & $\$ 24.0$ \\
\hline 6 & Russia & $\$ 21.0$ \\
\hline 7 & Canada & $\$ 14.4$ \\
\hline 8 & Japan & $\$ 11.0$ \\
\hline 9 & Spain & \\
\hline 10 & India & \\
\hline
\end{tabular}

In the Indian scenario Govt agencies viz. ISRO,DRDO,HAL and BEL have attained appreciable international competitive advantage while companies in the private sector in the aerospace field are comparatively is in nascent stages. For development they require very strong quality culture to bring in competitive advantage in their operations. As seen from the table at para 8 above, India occupies the 10th postion in the aerospace field whereas scope for India is very high. Study in this direction arises from the undermentioned factors.

- The necessity for improving the implementation steps of the aerospace standard in Indian industries so that they develop effective competitive advantage

- To enable Indian Aerospace industry to face challenges in the global market

- Improving the performance standards of the existing Indian Aerospace companies without incurring expenditure on additional infrastructure.

- Bring in Quality consciousness in process control methods of the various AS organisations.

\section{STATEMENT OF PROBLEM AND PURPOSE}

In the Indian scene maximum number of AS certified companies are established in Bangalore and hence this paper first covers the companies in Bangalore. Most organizations take great pride in obtaining certification and showing the certification to enter and remain in the aerospace field as it is quite a rewarding field internationally. Here all the procedures conforming to certification are meticulously carried out as the audit is quite tough. In the practical scene this becomes another set of operations for the organization department. Whether qualitative or quantitative results are achieved or not is a highly subjective phenomenon. Successfully addressing this issue can lead to the development of a healthy synergistic and productive environment in aerospace industries.

In brief, the statement of the problem is that due to adoption of AS standard there exists

- Increased demand of cost-effectiveness in operations

- High-cost involvement and global competition

- $\quad$ Stringent requirements set by the AS Standard

- Improving process performance without incurring extra overheads, and which is generally delegated to the Quality Assurance

- Instilling quality consciousness in professional performance of the organizational members

Statement of Purpose is to assess whether organisations are deriving any perceivable gains-tangible or intangibledue to the adoption of this stringent Standard. (This paper is limited to analysis of Bangalore companies only)

\section{OBJECTIVES OF THE STUDY}

- $\quad$ To study the level of performance of processes in aerospace standard certified organisations

- $\quad$ To find out whether perceivable results exist which are arising from aerospace standard implementation

To examine whether there are dominant principles which can ensure effectiveness in implementation of the standard!!

\section{METHODOLOGY OF RESEARCH}

Research Design is Descriptive Research. Sampling Design is probability sampling design. The scope of this paper is limited to the AS certified organizations in Bangalore as on 23 Dec 2018. OASIS lists more than 5000 AS organizations the world all over out of which 369 were organizations from Bangalore on the date when the survey commenced. This formed the population for the survey. The sample size required for this population for $95 \%$ confidence level is 181 which is finalized from the calculations. Still the questionnaire was forwarded to 300 companies to their official e-mail id. 186 responses were obtained which are analyzed through SPSS. Higher degree of accuracy is expected as the sample size is quite large.

\section{ANALYSIS \& RESULTS}

Reliability analysis implies that a scale should constantly reflect the construct it is measuring. The measured value of Cronbach's Alpha for survey questionnaire has good internal consistency of 0.821 and various dimensions included in the questionnaire also a have internal consistencies in the acceptable range with customer focus dimension having the highest value of 0.910 and engagement of people having the lowest value of with a value of 0.731 . Examining the type of registration of companies to which the respondents belong, it can be seen that majority of the respondents are from partnership firms (77.4\%) and 22.6 belong to Private ltd companies. The descriptive statistics regarding the tenure of the organization reveals that majority of companies, to which respondents belong, have been operating for more than 20 years $(92.5 \%)$ and only $7.5 \%$ of the companies operating for $10-20$ years

\section{MOTIVES FOR DEVELOPING QMS}

Interpretation of mean values indicate that "Fulfilling customer requirements " has highest mean of 6.05 which indicates out of 7 point scale, 6.05 respondents support this motive of QMS , followed by " To effectively and efficiently control activities " motive with mean value of 4.13. " To improve the company's prestige (e.g. image, 
reputation)" has the least mean score of 2.38 .

Standard deviation value indicates variability in opinion of respondents. Low value of standard deviation indicates that there is no much change in the opinion of respondents on the statement. In the above table, all the motives have standard deviation of value greater than 1 with " To enter the international market " having the highest standard deviation of 2.33 which indicates that the respondents have varied opinion to the motive and "To effectively and efficiently control activities " have the lowest standard deviation of 1.45 .

\section{Null Hypothesis $(\mathrm{HO})$ :}

There is no relationship between QMS principles and improvement

\section{Alternate Hypothesis(H1):}

There is relationship between QMS principles and improvement

\begin{tabular}{|c|c|c|c|}
\hline Variable 1 & Variable 2 & $\begin{array}{c}\text { Correlation } \\
\text { Coefficient }\end{array}$ & p-value \\
\hline $\begin{array}{c}\text { Perceived } \\
\text { improvement } \\
\text { due to adoption } \\
\text { of AS }\end{array}$ & Customer Focus & 0.886 & $0.000^{* *}$ \\
\hline & Leadership & 0.712 & $0.000^{* *}$ \\
\hline & $\begin{array}{c}\text { People } \\
\text { Engagement }\end{array}$ & 0.396 & $0.000^{* *}$ \\
\hline & $\begin{array}{c}\text { Process } \\
\text { Approach }\end{array}$ & 0.840 & $0.000^{* *}$ \\
\hline & $\begin{array}{c}\text { Decision } \\
\text { Making }\end{array}$ & 0.423 & $0.000^{* *}$ \\
\hline & $\begin{array}{c}\text { Relationship } \\
\text { Management }\end{array}$ & 0.241 & $0.000^{* *}$ \\
\hline & $\begin{array}{c}\text { Improvement } \\
\text { (Process) }\end{array}$ & 0.667 & $0.000^{* *}$ \\
\hline
\end{tabular}

** Correlation is significant at the 0.01 level (2-tailed).

Interpretation: Since $\mathrm{p}$ values are less than 0.01 , the correlation is significant at $1 \%$ level of significance. From the values it can be seen that perceived improvement has high correlation with customer focus $(\mathrm{r}=0.886)$, followed by Process approach $(\mathrm{r}=0.840)$ and leadership $(\mathrm{r}=0.712)$. The lowest values are being Relationship Management ( $\mathrm{r}=0.241)$ followed by People Engagement $(r=0.396)$.In order to identify the contribution of individual dimensions to the perceived improvement, regression analysis was done and the results are as follows

\begin{tabular}{|c|c|c|c|c|c|}
\hline $\begin{array}{c}\text { Dependent } \\
\text { Variable }\end{array}$ & $\begin{array}{c}\text { Independent } \\
\text { Variables }\end{array}$ & R2 & $\begin{array}{c}\text { Adjusted } \\
\text { R2 }\end{array}$ & $\begin{array}{c}\text { F } \\
\text { value }\end{array}$ & P value \\
\hline $\begin{array}{c}\text { Perceived } \\
\text { improvement } \\
\text { due to } \\
\text { adoption of } \\
\text { AS }\end{array}$ & & & & & \\
\hline & $\begin{array}{c}\text { Customer } \\
\text { Focus }\end{array}$ & 0.702 & 0.69 & 67.32 & $0.000^{*}$ \\
\hline & Leadership & & & & \\
\hline & $\begin{array}{c}\text { People } \\
\text { Engagement }\end{array}$ & & & & \\
\hline & $\begin{array}{c}\text { Process } \\
\text { Approach }\end{array}$ & & & & \\
\hline & $\begin{array}{c}\text { Decision } \\
\text { Making }\end{array}$ & & & & \\
\hline & $\begin{array}{c}\text { Relationship } \\
\text { Management }\end{array}$ & & & & \\
\hline & $\begin{array}{c}\text { Improvement } \\
\text { (Process) }\end{array}$ & & & & \\
\hline
\end{tabular}

Since $\mathrm{p}$ value $<0.05$, the model is significant at $5 \%$ level of significance. R2 value is 0.702 . Adjusted R2 value is 0.69 which means $69 \%$ of the variability in Perceived improvement due to adoption of AS is caused by listed dependent variables. The remaining $31 \%$ of variability is due to other unexplained factors. To understand independent variables contribution, $\mathrm{p}$ value was assessed which is as shown below.

\begin{tabular}{|c|c|c|}
\hline $\begin{array}{c}\text { Independent } \\
\text { Variable }\end{array}$ & Beta & P value \\
\hline Customer Focus & 0.614 & .000 \\
\hline Leadership & 0.523 & .011 \\
\hline People Engagement & 0.039 & .046 \\
\hline Process Approach & 0.556 & .000 \\
\hline Decision Making & 0.390 & .000 \\
\hline $\begin{array}{c}\text { Relationship } \\
\text { Management }\end{array}$ & 0.254 & .001 \\
\hline $\begin{array}{c}\text { Improvement } \\
\text { (Process) }\end{array}$ & 0.430 & .031 \\
\hline
\end{tabular}

Since $\mathrm{p}$ value of all independent variables are less than 0.05 , all the independent variables make significant contribution to the Perceived improvement due to adoption of AS. To understand individual independent variable contribution the value of beta is used. The value of beta can be interpreted as follows: "For every one unit increase in independent variable, the dependent variable changes by the vale of Beta"

Thus workplace improvement receives high contribution from Customer Focus, followed by Process Approach, Process Approach and Leadership. People Engagement and Relationship Management generate least contribution

\section{Null Hypothesis (HO):}

There is no significant difference in perception of improvement due to adoption of AS between Nature of quality policy groups

\section{Alternate Hypothesis (H1):}

There is significant difference in perception of improvement due to adoption of AS between Nature of quality policy groups

One Way Anova used to analyze the differences and results are as follows

\begin{tabular}{|c|c|c|c|}
\hline $\begin{array}{c}\text { Nature of } \\
\text { quality policy }\end{array}$ & N & Mean & Std. Deviation \\
\hline & & & \\
\hline Understandable & 85 & 45.2353 & 2.32813 \\
\hline Long & 77 & 43.7792 & 2.50591 \\
\hline Difficult & 24 & 44.8333 & 3.37080 \\
\hline Total & 186 & 43.6667 & 2.59244 \\
\hline
\end{tabular}

\section{ANOVA}

\begin{tabular}{|c|c|c|c|c|c|}
\hline & $\begin{array}{c}\text { Sum of } \\
\text { Squares }\end{array}$ & df & $\begin{array}{c}\text { Mean } \\
\text { Square }\end{array}$ & F & Sig. \\
\hline $\begin{array}{c}\text { Between } \\
\text { Groups }\end{array}$ & 49.459 & 2 & 24.730 & 3.791 & .024 \\
\hline $\begin{array}{c}\text { Within } \\
\text { Groups }\end{array}$ & 1193.874 & 183 & 6.524 & & \\
\hline Total & 1243.333 & 185 & & & \\
\hline
\end{tabular}




\section{A Research on the Effectiveness of Aerospace Quality Management System (Aqms) in the Aerospace Organisations in Bangalore}

\section{Interpretation}

Since $\mathrm{p}<0.05$, we reject null hypothesis at $5 \%$ level of significance.

Thus, Nature of quality policy influences the perception of improvement due to adoption of AS. From the mean values, it can be inferred that respondents perceive improvement due to adoption of AS when the quality policy is understandable (mean $=45.2353$ )

\section{Findings}

The following findings are derived from the study

a. From the values it can be seen that perceived improvement has high correlation with customer focus, followed by Process approach and leadership. The lowest values are Relationship Management followed by People Engagement. This means that companies having customer focus and process approach as well as leadership are able to obtain high level of improvement perceived in their organizational members.

b. With quality policy being understandable and easy for the organizational members, there is good perception of improvement in the organizational activities.

c. The analysis confirms the basic hypothesis that when planned activities incorporate QMS principles, there are perceivable improvements in the organization.

\section{Suggestions}

a. The study brings out that there is very close relation between the QMS principles and Perceivable improvements in an organization. It will be an effective step that if Top Management can closely analyse their quality objectives with respect to the requirements of their customers.

b. As matter of practice the philosophy of Plan-DoCheck-Act (PDCA) be incorporated in the AQMS implementation steps.

c. While undertaking the annual Management reviews realistic analysis of the state of the affairs be taken and only incremental enhancement of $\max 5 \%$ be planned annually rather than idealistic non-achievable targets.

d. At the time of planning to commence AQMS, realistic assessment of affairs on the Quality front be taken as the adoption of AQMS is a strategic decision for any organization. The resources may be earmarked on the basis of this assessment only.

\section{CONCLUSION}

It is brought out that the adoption of QMS principles in AQMS implementation can enhance awareness

In the Organizational members from the Topmost level till the junior most and thereby Perception of improvement in Organizational functioning will become a matter of culture rather than an additional burden. Accepting AQMS as a culture will become a reality if QMS Principles are made the basis for finalizing Quality Objectives. Adoption of AS Standard is to bring AQMS as a way of working which is the need of the hour. Principally the essential advantage is that no additional infrastructure expenses get encountered, only focus and sincere effort by the Top Management is needed to bring in changes in the method of working.

\section{REFERENCES}

1. ISO 9001:2015 \& ISO 9000:2015 Standards published by the ISO

2. Aerospace Standard AS 9100D\&ISO 17021-1 2015Standard for requirement for certifying organisations

3. Quality Management System for Defence Aeronautical Industry K.T. Thomas DGAQA, Ministry of Defence, Bangalore-560 017

4. Aerospace Quality Management System According To Selected Quality Standards Izabela Sprycha Maria CurieSk?odowska University, Poland

5. Implementation of a quality management system (QMS) according to the ISO 9000 family in a Greek small-sized winery: A case study D. Aggelogiannopoulos, E.H. Drosinos, P. Athanasopoulos Agricultural University of Athens, 75, Iera Odos Street,Votanicos, GR-118 55 Athens, Greece

6. Analysis of Relationship between Quality Management System and Design Assurance System ZhaoZhang, TaoSong, JiashanSong

7. Important Aspects Of Continuous Quality Improvement In Slovak Enterprises Marta KU?EROVÁ, Jaromíra VA?OVÁ, Helena FIDLEROVÁ 